\title{
A Heat Unit Accumulation Method for Predicting Cucumber Harvest Date
}

\author{
Katharine B. Perry and
}

Todd C. Wehner ${ }^{1}$

Additional index words. growingdegree days

Summary. The use of a previously developed model for predicting harvest date in cucumber production systems is described. In previous research we developed a new method using daily maximum temperatures in heat units to predict cucumber harvest dates. This method sums, from planting to harvest, the daily maximum minus a base temperature of $60 \mathrm{~F}(15.5 \mathrm{C})$, but if the maximum is $>90 \mathrm{~F}(32 \mathrm{C})$ it is replaced by $90 \mathrm{~F}$ minus the difference between the maximum and 90F. This method was more accurate than counting days to harvest in predicting cucumber harvest in North Carolina, even when harvest was predicted using 5 years of experience for a particular location and planting date.

\footnotetext{
A ccurately predicting harvest $\triangle$ date and a crop's developmen1 tal stage has widespread application for improving crop management, e.g., scheduling labor, machinery, integrated pest management practices, and timely production at high market pricing. The concept of heat summation to achieve this prediction for vegetable crops dates back to 1929 when it was found that peas flowered after receiving a particular amount of heat, regardless of the number of days involved (Boswell, 1929). The research that followed focused on what we

Professors, Department of Horticultural Science, North Carolina State University, Raleigh, NC 27695-7609.

The cost of publishing this paper was defrayed in part by the payment of page charges. Under postal regulations, this paper therefore mast be hereby marked advertisement solely to indicate this fact.
} 
Table 1. Predicted heat unit (HU) accumulation, harvest date, and total days from planting to harvest (DTH) for gynoecious pickling cucumber planted in Clinton, N.C., from 1 Mar. to 2 Sept.

\begin{tabular}{|c|c|c|c|c|c|}
\hline \multicolumn{2}{|c|}{$\begin{array}{l}\text { Planting } \\
\text { date }\end{array}$} & \multirow{2}{*}{$\begin{array}{l}\mathrm{HU} \\
149\end{array}$} & \multirow{2}{*}{$\begin{array}{c}\begin{array}{c}\text { Harvest } \\
\text { date }\end{array} \\
\text { May }\end{array}$} & & \multirow{2}{*}{$\frac{\text { DTH }}{81}$} \\
\hline March & 1 & & & 21 & \\
\hline & 2 & 155 & & 21 & 80 \\
\hline & 3 & 161 & & 21 & 79 \\
\hline & 4 & 168 & & 22 & 79 \\
\hline & 5 & 175 & & 22 & 78 \\
\hline & 6 & 182 & & 22 & 77 \\
\hline & 7 & 186 & & 22 & 76 \\
\hline & 8 & 192 & & 23 & 76 \\
\hline & 9 & 198 & & 23 & 75 \\
\hline & 10 & 202 & & 23 & 74 \\
\hline & II & 209 & & 23 & 73 \\
\hline & 12 & 216 & & 24 & 73 \\
\hline & 13 & 225 & & 24 & 72 \\
\hline & 14 & 237 & & 25 & 72 \\
\hline & 15 & 247 & & 25 & 71 \\
\hline & 16 & 256 & & 25 & 70 \\
\hline & 17 & 262 & & 26 & 70 \\
\hline & 18 & 266 & & 26 & 69 \\
\hline & 19 & 273 & & 26 & 68 \\
\hline & 20 & 281 & & 27 & 68 \\
\hline & 21 & 290 & & 27 & 67 \\
\hline & 22 & 297 & & 27 & 66 \\
\hline & 23 & 301 & & 28 & 66 \\
\hline & 24 & 308 & & 28 & 65 \\
\hline & 25 & 315 & & 28 & 64 \\
\hline & 26 & 322 & & 29 & 64 \\
\hline & 27 & 328 & & 29 & 63 \\
\hline & 28 & 337 & & 29 & 62 \\
\hline & 29 & 346 & & 30 & 62 \\
\hline & 30 & 358 & & 30 & 61 \\
\hline & 31 & 370 & & 31 & 61 \\
\hline \multirow[t]{27}{*}{ April } & 1 & 384 & & 31 & 60 \\
\hline & 2 & 397 & June & l & 60 \\
\hline & 3 & 412 & & 1 & 59 \\
\hline & 4 & 428 & & 2 & 59 \\
\hline & 5 & 443 & & 3 & 59 \\
\hline & 6 & 454 & & 3 & 58 \\
\hline & 7 & 465 & & 3 & 57 \\
\hline & 8 & 476 & & 4 & 57 \\
\hline & 9 & 486 & & 4 & 56 \\
\hline & $\underline{10}$ & $\underline{495}$ & & $\underline{5}$ & 56 \\
\hline & 11 & 506 & & 5 & 55 \\
\hline & 12 & 521 & & 6 & 55 \\
\hline & 13 & 537 & & 6 & 54 \\
\hline & 14 & 552 & & 7 & 54 \\
\hline & 15 & 567 & & 8 & 54 \\
\hline & 16 & 583 & & 8 & 53 \\
\hline & 17 & 596 & & 9 & 53 \\
\hline & 18 & 609 & & 9 & 52 \\
\hline & 19 & 624 & 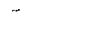 & 10 & 52 \\
\hline & 20 & 641 & & 10 & 51 \\
\hline & 21 & 657 & & 11 & 51 \\
\hline & 22 & 673 & & 12 & 51 \\
\hline & 23 & 690 & & 12 & 50 \\
\hline & 24 & 707 & & 13 & 50 \\
\hline & 25 & 723 & & 14 & 50 \\
\hline & 26 & 739 & & 14 & 49 \\
\hline & 27 & 755 & & 15 & 49 \\
\hline
\end{tabular}

now call growing-degree days.

Growing-degree days are determined by calculating the average of the maximum and minimum air temperature for a day and subtracting a base temperature, usually the minimum germination temperature for the crop. Because often more than 1 growing-degree day occurs on a given day (one 24-h period), the term growing degree days is confusing. Researchers have developed more complex meth-

\begin{tabular}{|c|c|c|c|c|c|}
\hline \multicolumn{2}{|c|}{$\begin{array}{l}\text { Planting } \\
\text { date }\end{array}$} & \multicolumn{3}{|c|}{ Harvest } & DTH \\
\hline & 28 & 774 & & 16 & 49 \\
\hline & 29 & 791 & & 16 & 48 \\
\hline & 30 & 807 & & 17 & 48 \\
\hline May & $\mathrm{I}$ & 825 & & 18 & 48 \\
\hline May & 2 & 843 & . June & 19 & 48 \\
\hline & 3 & 861 & & 19 & 47 \\
\hline & 4 & 878 & & 20 & 47 \\
\hline & 5 & 896 & & 21 & 47 \\
\hline & 6 & 914 & & 21 & 46 \\
\hline & 7 & 935 & & 22 & 46 \\
\hline & 8 & 954 & & 23 & 46 \\
\hline & 9 & 972 & & 24 & 46 \\
\hline & 10 & 988 & & 24 & 45 \\
\hline & 11 & 1006 & & 25 & 45 \\
\hline & 12 & 1028 & & 26 & 45 \\
\hline & 13 & 1050 & & 27 & 45 \\
\hline & 14 & 1072 & & 27 & $44^{\circ}$ \\
\hline & 15 & 1093 & & 28 & 44 \\
\hline & 16 & 1113 & & 29 & 44 \\
\hline & 17 & 1135 & & 30 & 44 \\
\hline & 18 & 1155 & July & 1 & 44 \\
\hline & 19 & 1176 & & 1 & 43 \\
\hline & 20 & 1199 & & 2 & 43 \\
\hline & 21 & 1220 & & 3 & 43 \\
\hline & 22 & 1242 & & 4 & 43 \\
\hline & 23 & 1265 & & 5 & 43 \\
\hline & 24 & 1290 & & 6 & 43 \\
\hline & 25 & 1311 & & 7 & 43 \\
\hline & 26 & 1331 & & 7 & 42 \\
\hline & 27 & 1352 & & 8 & 42 \\
\hline & 28 & 1373 & & 9 & 42 \\
\hline & 29 & 1396 & & 10 & 42 \\
\hline & 30 & 1420 & & 11 & 42 \\
\hline & $\underline{31}$ & $\underline{1445}$ & & 12 & 42 \\
\hline June & 1 & 1471 & & 13 & 42 \\
\hline & 2 & 1496 & & 14 & 42 \\
\hline & 3 & 1522 & & 15 & 42 \\
\hline & 4 & 1544 & & 16 & 42 \\
\hline & 5 & 1568 & & 16 & 41 \\
\hline & 6 & 1593 & & 17 & 41 \\
\hline & 7 & 1619 & & 18 & 41 \\
\hline & 8 & 1645 & & 19 & 41 \\
\hline & 9 & 1670 & & 20 & 41 \\
\hline & 10 & 1696 & & 21 & 41 \\
\hline & 11 & 1719 & & 22 & 41 \\
\hline & 12 & 1743 & & 23 & 41 \\
\hline & 13 & 1768 & & 24 & 41 \\
\hline & 14 & 1793 & & 25 & 41 \\
\hline & 15 & 1818 & & 26 & 41 \\
\hline & 16 & 1844 & & 27 & 41 \\
\hline & 17 & 1869 & & 28 & 41 \\
\hline & 18 & 1894 & & 29 & 41 \\
\hline & 19 & 1919 & & 30 & 41 \\
\hline & 20 & 1946 & & 31 & 41 \\
\hline & 21 & 1972 & Aug. & 1 & 41 \\
\hline & 22 & 1997 & & 2 & 41 \\
\hline & 23 & 2021 & & 3 & 41 \\
\hline & 24 & 2048 & & 4 & 41 \\
\hline & 25 & 2074 & & 5 & 41 \\
\hline & 26 & 2099 & & 6 & 41 \\
\hline & 27 & 2125 & & 7 & 41 \\
\hline & 28 & 2150 & & 8 & 41 \\
\hline & 29 & 2176 & & 9 & 41 \\
\hline
\end{tabular}

\begin{tabular}{|c|c|c|c|c|c|}
\hline \multicolumn{2}{|c|}{$\begin{array}{l}\text { Planting } \\
\text { date }\end{array}$} & $\mathrm{HU}$ & \multicolumn{2}{|c|}{ Harvest } & DTH \\
\hline & 30 & 2204 & & 10 & 41 \\
\hline \multirow[t]{30}{*}{ July } & 1 & 2230 & & 11 & 41 \\
\hline & 2 & 2256 & & 12 & 41 \\
\hline & 4 & 2308 & & 14 & 41 \\
\hline & 5 & 2335 & & 15 & 41 \\
\hline & 6 & 2360 & & 16 & 41 \\
\hline & 7 & 2386 & & 17 & 41 \\
\hline & 8 & 2412 & & 18 & 41 \\
\hline & 9 & 2438 & & 19 & 41 \\
\hline & 10 & 2464 & & 20 & 41 \\
\hline & 11 & 2490 & & 21 & 41 \\
\hline & 12 & 2516 & & 22 & 41 \\
\hline & 13 & 2542 & & 23 & 41 \\
\hline & 14 & 2569 & & 24 & 41 \\
\hline & 15 & 2595 & & 25 & 41 \\
\hline & 16 & 2621 & & 26 & 41 \\
\hline & 17 & 2647 & & 27 & 41 \\
\hline & 18 & 2674 & & .28 & 41 \\
\hline & 19 & 2701 & & 29 & 41 \\
\hline & 20 & 2727 & & 30 & 41 \\
\hline & 21 & 2752 & & 31 & 41 \\
\hline & 22 & 2777 & Sept. & 1 & 41 \\
\hline & 23 & 2802 & & 2 & 41 \\
\hline & 24 & 2829 & & 3 & 41 \\
\hline & 25 & 2855 & & 4 & 41 \\
\hline & 26 & 2883 & & 5 & 41 \\
\hline & 27 & 2909 & & 6 & 41 \\
\hline & 28 & 2936 & & 7 & 41 \\
\hline & 29 & 2962 & & 9 & 42 \\
\hline & 30 & 2988 & & 10 & 42 \\
\hline & 31 & 3015 & & 11 & 42 \\
\hline \multirow[t]{31}{*}{ Aug. } & 1 & 3041 & & 12 & 42 \\
\hline & 2 & 3068 & & 13 & 42 \\
\hline & 3 & 3095 & & 14 & 42 \\
\hline & 4 & 3121 & & 15 & 42 \\
\hline & 5 & 3147 & & 16 & 42 \\
\hline & 6 & 3173 & & 17 & 42 \\
\hline & 7 & 3200 & & 19 & 43 \\
\hline & 8 & 3227 & & 20 & 43 \\
\hline & 9 & 3253 & & 21 & 43 \\
\hline & 10 & 3280 & & 22 & 43 \\
\hline & 11 & 3305 & & 23 & 43 \\
\hline & 12 & 3331 & & 24 & 43 \\
\hline & 13 & 3357 & & 26 & 44 \\
\hline & 14 & 3384 & & 27 & 44 \\
\hline & 15 & 3409 & & 28 & 44 \\
\hline & 16 & 3436 & & 29 & 44 \\
\hline & 17 & 3462 & Oct. & 1 & 45 \\
\hline & 18 & 3487 & & 2 & 45 \\
\hline & 19 & 3512 & & 4 & 46 \\
\hline & 20 & 3536 & & 5 & 46 \\
\hline & 21 & 3561 & & 6 & 46 \\
\hline & 22 & 3587 & & 8 & 47 \\
\hline & 23 & 3610 & & 10 & 48 \\
\hline & 24 & 3637 & & 11 & 48 \\
\hline & 25 & 3662 & & 13 & 49 \\
\hline & 26 & 3688 & & 15 & 50 \\
\hline & 27 & 3716 & & 17 & 51 \\
\hline & 28 & 3742 & & 19 & 52 \\
\hline & 29 & 3768 & & 21 & 53 \\
\hline & 30 & 3794 & & 23 & 54 \\
\hline & 31 & 3818 & & 25 & 55 \\
\hline \multirow[t]{2}{*}{ Sept. } & 1 & 3842 & & 27 & 56 \\
\hline & 2 & 3868 & & 29 & 57 \\
\hline
\end{tabular}

ods of heat summation, and many now use the term heat unit (HU) to describe this concept.

Recently progress has been made in the development of weather-based (predominantly temperature) models that predict harvest or other developmental stages. It is assumed that, although moisture, fertility, and pest and disease incidence affect crop development, it is predominantly driven by temperature, which is linked to moisture. This type of model addresses the timing of crop, disease, or pest development. It does not address yield or quality.

Recent efforts have incorporated techniques to improve the simulation of the diurnal temperature change. The original formula assigns half the day to the maximum temperature and half to the minimum temperature, when actually the temperature changes 
Table 2. Target heat unit (HU) accumulation from planting to first harvest for pickling cucumber cultivars of two maturity groups.

Early season maturing, $\mathrm{HU}=1053$
Blitz
Calico
Calypso
Carolina
Cascade
Castlepik
Chemset
Commander
Earlipik 14
Explorer
Fremont
Greenpak
Gynomite
Lucky Strike
Medusa
Multipik
Panorama
Pikmaster
Pinnacle
Regal
Reliance
Salvo
Sampson
Score
Southern Belle
Tamor
Target
Tempo
Totem
Triple Crown
Triplemech
Midseason maturing, HU = 1125
Clinton
Pennant
Saladin
SMR 58
Sumter
Triple Pak
Wisconsin SMR 18

throughout the day. New techniques have added the concept of ceiling temperatures, above which plant growth stops and reduced ceiling temperatures, above which plant growth declines.

Pickling and slicing cucumbers usually are harvested two to three times per week for 3 to 4 weeks in North Carolina. Harvests can be as few as once per week (Wisconsin), and extend as long as 10 weeks (Ohio, California). Also, once-over harvest of pickling cucumbers is common in areas with uniform production conditions (Michigan, Wisconsin, Delaware), but
Table 3. Target heat unit (HU) accumulation from planting to first harvest for freshmarket cucumber cultivars of three maturity groups.

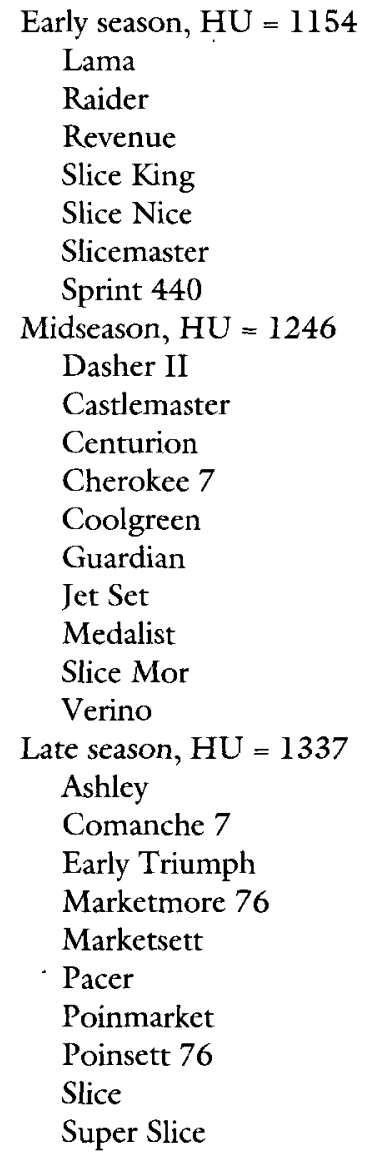

this method of harvest results in a low percentage of small sizes. The trend in the past decade is to harvest fewer times in multiple-harvest systems, because new cultivars provide a more concentrated fruit set and because harvest costs are becoming a larger part of total production costs.

In previous research, in a comparison of 14 methods for determining heat unit requirements, Perry et al. (1986) determined that the most accurate prediction method was to sum, over days from planting to harvest, the difference between the daily maximum and abase temperature of $60 \mathrm{~F}(15.5 \mathrm{C})$, but if the maximum exceeded $90 \mathrm{~F}$ (32C), it was replaced by $90 \mathrm{~F}$ (32C) minus the difference between the maximum and $90 \mathrm{~F}$ (32C), before subtracting the base. These base and ceiling values were determined from an analysis of five base and five ceiling temperature values. To determine the units for each day the following equations were used:
If maximum air temperature is $90 \mathrm{~F}$ (32C), HU $=$ max $-60 \mathrm{~F}$

If maximum air temperature is greater than $90 \mathrm{~F}(32 \mathrm{C})$, then $\mathrm{HU}=(90-$ $(\max -90))-60$

In a subsequent independent test of this method, it was determined to be more accurate than counting days to harvest for processing cucumbers (Perry and Wehner, 1990).

To use this model in North Carolina, tables of daily normal HU accumulation, based on climatological data of daily maximum and minimum air temperatures of 1961-90 (Owenby and Ezell, 1992), and the associated harvest dates were developed for planting dates from 1 Mar. to 2 Sept. (Table 1). The table is designed for use with midseason, pickling-type cultivars, e.g., HU target of 1125. However, a correction factor should be used if the cultivar is of different maturity or is a slicing type (Tables 2 and 3 ). A lookup table may seem rather low-tech in the current computerized world, but its convenience supports this format for field applications. The table could be computerized.

The following procedure enables the user to update the harvest prediction based on observed daily air temperatures. First, calculate the HU for each day using Eqs. [1] and [2], above. Second, keep a running total of these HUs beginning on the planting date. Third, update the harvest date prediction by subtracting the current total from 1125 . Add the result to the accumulated HUs from the table for the current day. Find the number closest to this result in the HU column of the table and read the associated harvest date. This is the updated harvest date prediction.

For example, using the sample table for the Clinton location, a midseason-maturing, pickling-type cultivar, and a planting date of $10 \mathrm{Apr}$. (Table 1), the initial harvest date prediction is 5 June. If a 25 Apr. update is carried out, and the HU accumulation on 25 Apr. is 400, then the predicted harvest date would change. Normally the total would be $723-495=228$ (note, the amount accumulated from 1 Mar. to 10 Apr. must be subtracted to get the units accumulated from 1125 Apr.):

a) $1125-400=725$.

b) $723+725=1448$.

c) Closest number to 1448 is 1445 .

d) Updated harvest date is 31 May. 
Any attempt to explain the entire developmental and maturation process of a particular cultivar using a temperature model alone is an oversimplification. Moisture, fertility, and pest and disease incidence, as well as the weather variables, certainly are involved in determining the crop's development rate. These factors are major determinants of yield and quality, but for HU modelling, temperature is assumed to be the major driver of growth rate. Results of current work show that HU modelling can be applied to operational systems.

\section{Literature Cited}

Boswell, V.R. 1929. Factors influencing yield and quality of peas. Maryland Agr. Expt. Sta. (Beltsville) Bul. 306.

Owenby, J.R. and D.S. Ezell. 1992. Monthly station normals of temperature, precipitation, and heating and cooling degree days 1961-90. Climatography of the U.S. No. 81. U.S. Dept. Commerce, National Climatic Data Center, Asheville, N.C.

Perry, K.B., T.C. Wehner, and GL. Johnson. 1986. Comparison of 14 methods to determine heat unit requirements for cucumber harvest. HortScience 21:419-423.

Perry, K.B. and T.C. Wehner. 1990. Prediction of cucumber harvest date using a heat unit model. HortScience 25:405-406. 